\title{
Coaching Behaviors and Athlete Motivation: Female Softball Athletes' Perspectives
}

\author{
Megan M. BUNING ${ }^{1} \bullet$ Melissa A. THOMPSON ${ }^{2}$
}

Derspectives of female collegiate softball athletes $(\mathrm{n}=41)$ attending
universities $(\mathrm{n}=25)$ in the United States classified as National Collegiate Athletic Association (NCAA) Division I teams, were examined in this study. Using Self-determination theory (SDT; Ryan \& Deci, 2000) as a guide, structured interviews were conducted to assess athletes' perspectives of head coach behaviors that influenced competence and motivation. Content analysis followed existential phenomenological interpretation methods and revealed three primary themes that influenced motivation: athletes' perceived competence, coach-related factors (e.g., behaviors, strategies), and coachathlete communication. Athletes acknowledge the head coach was a major influence on perceptions of competence. Perceptions of coach-athlete communication (including verbal communication) were the greatest influence on athlete motivation. Athletes were more motivated to perform when the head coach's communication was clear and direct. Athletes' motivation was most negatively influenced when the coach avoided communication or ignored athletes after a performance attempt. These findings are further explored as they relate to coaching interventions.

Keywords: motivation, coaching, communication

${ }^{1}$ College of Education, Augusta University (Georgia Regents University), Augusta, GA, USA

2 The University of Southern Mississippi, Hattiesburg, MS, USA 
The sport environment is one where the coach can have a strong influence on the worth and memory of the athletic experience (Bell, 1997) including enjoyment level, memories of playing time, the athlete's preparation to continue competition (Smith, Smoll, \& Barnett, 1995), overall well-being (Jowett \& Cramer, 2010), and strategies the athlete uses to set and attain performance goals (Smith, Ntoumanis, \& Duda, 2010). Coaches play several roles - teacher, mentor, leader - and the nature of their interactions with athletes can greatly influence athletes' motivation and enjoyment of sport participation (Wang, Koh, \& Chatzisarantis, 2009). It is no surprise, therefore, that many athletes name their coach as an important figure in their life, and this relationship has routinely been found to be a factor related to athlete performance (Amorose, 2003; Jowett, 2007; Jowett \& Cramer, 2010).

To this end, previous research has focused on a variety of coach-related factors (e.g., leadership styles, behaviors, motivational climates, relationships) in relation to athletes' self-determined motivation. Amorose and Horn $(2000,2001)$ and Hollembeak and Amorose (2005) have demonstrated the importance of coach leadership style and the influence on athlete motivation and perceptions of feedback style. Discussion of coach influence on motivational climate has produced much support for the benefits of and athlete preference for creating mastery or autonomous team climates (Martin, Dale, \& Jackson, 2001; Smith et al., 2010; Turman, 2003b; White Kavussanu, \& Guest, 2006). In addition, Jowett and Cramer's (2010) study of female youth athletes provided support for the perceived meaningfulness of the coach-athlete relationship to predict physical well-being descriptors, and perceived conflict within the coach-athlete relationship resulted in lower levels of psychological competence and overall performance. The longer athletes had been involved in their sport, the more they desired a positive, supportive relationship with their coach.

Just as supportive coach-athlete relationships are an important focus of research, so are negative relationships. Critical or disciplinary feedback from a coach can create high levels of negative outcomes for athletes, and athletes complain about the coach's feedback style as a reason for decreased levels of performance and enjoyment (Gearity, 2011; Gearity \& Murray, 2010; Greenleaf, Gould, \& Dieffenbach, 2001; Turman, 2003a). Because the nature of coachathlete interactions can greatly influence several psychological processes, the nature of the relationship is critical to the athlete's career and success (Smith et al., 2010; Wang et al., 2009). One key element coaches have the power to influence, but may not yet understand fully the processes involved, is athlete motivation. Understanding why and how athletes are motivated to continue playing is a critical issue for coaches (Vallerand \& Fortier, 1998). Self-determination theory 
(SDT, Deci \& Ryan, 1985; Ryan \& Deci, 2000) provides a popular framework for examining environmental conditions that influence motivation.

Understanding motivation and SDT. Generally, motivation refers to an internal process that initiates effort and direction toward a behaviour (Weiss \& Ferrer Caja, 2002). SDT explains motivation as flowing along a continuum ranging from the absence of motivation (i.e., amotivation), through four types of extrinsic regulations each becoming more self-determined, to intrinsic motivation (Ryan \& Deci, 2000). Further, individuals have three basic needs that should be met to enhance self-determined motivation (autonomy, competence, relatedness). External factors (e.g., coach behaviors and feedback, team climate) can influence these needs and ultimately influence self-determined motivation (Ryan \& Deci, 2000).

Self-determined types of motivation can have positive effects on behaviour, but intrinsic motivation has had the strongest correlation with desired behaviour (Ryan \& Connell, 1989; Vallerand \& O'Conner, 1989), and is constantly being influenced by social and environmental factors (Ryan \& Deci, 2000). Research on the benefits of intrinsic motivation has been exhaustive, particularly in the educational and athletic domain. In general, people who are more selfdetermined have more interest, excitement, and confidence toward the specific behaviour that has led to improvements in performance, self-esteem, and general well-being (Deci \& Ryan, 1991; Hein, Müür, \& Koka, 2004). Within the athletic environment, studies indicate that athletes who participate for more selfdetermined reasons display more adaptive behaviors (e.g., invest more effort, higher levels of concentration, persistence) and perform better than athletes who are less self-determined (Beauchamp, Halliwell, Fournier, \& Koestner, 1996; Pelletier, Fortier, Vallerand, \& Brière, 2001). Investigating the sources of self-determined motivation, then, is critically important.

Athletes must overcome many obstacles in their journey toward sport excellence, and for them to be successful they must possess both physical and psychological strength including the ability to perform successfully or correctly (sport competence). Some researchers have focused on the mediating effects of competence on intrinsic motivation (Amorose \& Horn, 2000; 2001). Amorose (2003) found college athletes perceived their coach as the most important source of competence information above teammates and parents. Hollembeak and Amorose (2005) demonstrated how coaching behaviors could predict perceptions of competence. Consistent with SDT, athletes' perceptions of their coach's behaviors and feedback type can influence motivational drive (Amorose \& Horn, 2000; Pensgaard \& Roberts, 2002). More support is emerging indicating this generation of athletes prefers frequent positive training and instructional 
feedback, autonomy supportive environments, and democratic leadership styles (Hodge, Henry, \& Smith, 2014; Hollembeak \& Amorose, 2005; Sherman, Fuller, \& Speed, 2000; Turman, 2003b). The common theme from this line of research is the coach is an important factor in athletes' motivation. The type of motivation athletes' possess will greatly influence the athlete's sport experience (Vallerand, 2000), and while coaches are responsible for shaping athletic talent and strength, they are also responsible for facilitating athletes' motivation to perform.

Significance of study. Few recent studies have thoroughly examined highly competitive, female athletes with regard to motivation and perceived coaching behaviour, and those who have examined collegiate athletes' preferences of coaching behaviors used quantitative methods (Beam, Serwatka, \& Wilson, 2004; Horn, Bloom, Berglund, \& Packard, 2011; Riemer \& Toon, 2001; Sherman et al., 2000). Although all conclude various characteristics (gender of athlete, social and environmental factors) contribute to preferred coaching behaviour or leadership style, none of these studies capture the athlete's perspective of specific coaching behaviors that influence female athletes' motivation. Qualitative researchers are starting to place more emphasis on the athletes' perspectives around this topic (Gearity \& Murray, 2010), but capturing collegiate female athletes' perspectives has not been a priority in the literature. Acknowledging the athlete's voice about how coaches influence motivation provides the depth necessary to support the quantitative studies, resulting in a more holistic analysis of coach behaviors and athlete motivation.

Males and females are unique in their motivation to participate in sport (Duda, 1989), perceptions of athletic competence (Hollembeak \& Amorose, 2005), and preference for coaching behaviors (Faster \& Pfister, 2000; Martin et al., 2001); therefore specific types of coaching behaviors necessary to foster an environment for intrinsic growth should be considered independently. Generally, males and females are motivated differently to participate in an action (Duda, 1989). In today's world, female sports participation is rapidly growing as evident at the global level by the increase in female participation in the 2012 Olympics (Olympic Movement, 2014); however, the increase in female athletes does not translate to an increase in female coaches. Specific to the sport of softball, in the United States alone, more than 31\% of female collegiate teams are coached by male coaches with close to $50 \%$ of Division I softball coaches being male (LaVoi, 2014). Considering this imbalance, it is important to examine the specific factors female athletes identify as being related to their motivation to play. The sport of softball has a long history (Athnet, 2014), consists of large numbers of female athletes per team, is rapidly growing in popularity (Flynn, 1995), yet has not been isolated for research. These athletes' perspectives could provide insight of this generation of athletes for coaches of female athletes at all levels. Considering 
these variables, the purpose of this study was to qualitatively examine female softball athletes' perceptions of how coach behaviors influence their motivation to play softball.

\section{Method}

This study was conducted as a qualitative inquiry with a phenomenological focus rather than phenomenological methods (Patton, 2002). Although both are important, there are differences in these types of studies. This portion of the study sought to capture athletes' perspectives of the phenomenon of the event defined as coach-influenced motivation. Specifically, the focus was to capture athletes' perspectives and experiences of current coaching behaviors or actions that enhance or suppress motivation to play softball. This study was guided by the research questions: How do athletes perceive their head coaches to affect their motivation to continue playing softball for their current team? What types of coaching behaviors do athletes perceive to alter their motivation to play softball?

\section{Participants}

Purposive, emergent sampling techniques attracted 41 collegiate female softball athletes $\left(M_{\text {age }}=19.73, \mathrm{SD}=1.27\right)$ who were members of intercollegiate Division 1 softball $^{\text {age }}$ teams during the fall of 2012. The majority of athletes identified as Caucasian (87.8\%) with remaining athletes as Hispanic $(9.8 \%)$ and African American (2.4\%). The sample included starters (75.6\%) and non-starters (24.4\%) from all possible positions on a softball team (e.g., pitcher, catcher, infield, outfield). The majority of athletes $(58.5 \%)$ had played for their current head coach for less than one year $(M=1.01, S D=1.02)$.

Recruitment and procedures. Athletes were recruited for participation with the assistance from male $(n=6)$ and female $(n=19)$ head coaches of a randomly selected sample of Division I softball $(\mathrm{n}=25)$ teams that were part of a larger mixed methods dissertation study examining similar relationships specific to athletes in coach-designated expectation groups. After approval from the Institutional Review Board, the researcher sent an electronic letter of invitation to head coaches describing the purpose, procedures, and instructions. Coaches were asked to forward an email containing a link to a questionnaire to all athletes on the current roster requesting participation and consent to participate in the larger study. Athletes provided demographic information and voluntarily indicated interest in participating in an interview for this study. Willing athletes provided a university issued email address used by the researcher to arrange an email or phone interview. 
Ethical considerations. Identifying information was deleted from all documents and the researcher's online email account after interviews were arranged. Athletes chose a pseudonym prior to data collection that was retained for the completion of the study. The primary researcher used a voice-recorder to ensure accuracy of information for phone interviews. All interviews were permanently deleted at the conclusion of the study. A requirement for coaches to participate in the larger study was coaches would guarantee athletes could participate voluntarily without coercion.

\section{Data Collection}

A structured interview protocol was developed consisting of 12 open-ended retrospective questions with a maximum of three probe questions (Côte, Ericsson, \&Law, 2005). The decision to implement structured interview questions was made for two reasons: (a) to maintain consistency between the two different methods used to conduct interviews (email vs. phone), and (b) the primary researcher's inexperience with interview techniques. Although structured questions are not typically recommended for qualitative inquiry (Cresswell, 2009), the researchers believe the questions allowed for participant responses to adequately reflect perspectives and illicit thick descriptions of experiences. The interview protocol was reviewed and critiqued by three expert researchers in the field of sport psychology. Consistent with phenomenological interviewing techniques, the first question was designed to generate a variety of descriptive responses by asking athletes to describe their softball background (Pollio, Henley, \& Thompson, 1997). The remaining questions were designed to directly and indirectly assess the athletes' perspective of the impact environmental influences, including their head coach's behaviors had on their motivation to play softball and competence of their softball playing ability. Athletes were provided a choice between a phone or email interview to enhance access to athletes and accommodate their comfort levels with sharing information (Opdenakker, 2006). Phone interviews lasted an average of 25 minutes, and email interviews were returned within one week of receipt. The interview guide was pilot tested with female collegiate athletes from non-participating institutions to ensure the questions were clear and asked what the researcher intended. At the beginning of each interview, athletes were given a detailed description of the study, were reminded of their rights as a participant and were asked to confirm their voluntary participation in the interview. All interviews were conducted during the fall practice season by phone $(53.7 \%)$ or email correspondence $(46.3 \%)$. 


\section{Data Analysis and Trustworthiness}

Each audio-recorded interview was transcribed verbatim within two days of the original interview. Researcher notes to capture special meaning or emphasis placed on certain words accompanied recorded interviews. Member checking occurred by emailing athletes an executive summary of their responses within two days of the completion of the interview to ensure accurateness and completeness (Patton, 2002). The researcher maintained a journal to record personal thoughts throughout the study, and each week discussed any notes with an external professional with athletic experience to assist in controlling for researcher bias (Patton, 2002).

Data analysis followed existential phenomenological interpretation methods and involved continuously relating parts of text to the text as a whole (Patton, 2002). All transcripts were read three times in their entirety to gain a sense of the text as a whole with initial coding beginning on the fourth read and involved identifying meaningful patterns and statements. On each subsequent reading, similar patterns and statements from each transcript were grouped under the corresponding code to create sub-themes. Codes were adjusted as necessary by identifying convergent and divergent codes on three separate occasions (Patton, 2002). Finally, interview responses were grouped according to the question asked, and each response category was evaluated to form an overarching theme until each response was grouped into an appropriate theme. Each participant's responses were reviewed and compared to all other participants to identify emerging themes, and all themes and codes were continuously referenced to the original transcript. After these steps were completed, two external coders were asked to verify responses under each theme until a consensus was met. After themes were assigned, thematic validity was assessed by a third party holding a terminal degree higher education administration and with experience in qualitative methods (Patton, 2002). A thematic framework was developed as themes emerged that guided the analysis, and SDT and existing literature were used to compare emerging themes to help protect against researcher bias (Cresswell, 2009). The use of the computer software, N*Vivo 9 (NVivo, 2010) was used organize the content analysis process and assist with trustworthiness (Sinkovics, 2008).

\section{Findings}

Considering the limited qualitative research surrounding this topic, inductive content analysis was used to explore the data (Baker, Wuest, \& Stern, 1992). Content analysis revealed athletes for this study were predominantly self-determined in their motivation to play softball $(87.8 \%)$. Athletes reported 
primarily being motivated to play for their current team for reasons associated with: (a) value placed on relationships with teammates, (b) excitement or enjoyment of the sport itself, and (c) to win or be the best. Three superordinate themes emerged (reported by at least $44 \%$ of the sample) that influenced athletes' motivation either as an enhancing or inhibiting aspect: (a) perceived competence or confidence, (b) coach-related factors, and (c) perceived coachathlete communication. In addition subordinate themes emerged that identified more specific information. Examples of athletes' responses for each theme are presented in Table 1.

\section{Table 1}

\section{Summary of Superordinate and Subordinate Themes with Examples}

\begin{tabular}{|c|c|c|}
\hline $\begin{array}{l}\text { Superordinate } \\
\text { Themes }\end{array}$ & $\begin{array}{l}\text { Subordinate } \\
\text { Themes }\end{array}$ & Example \\
\hline \multirow{2}{*}{$\begin{array}{l}\text { Perceived } \\
\text { competence }\end{array}$} & Coach (37) & $\begin{array}{l}\text { 'It [competence] depends on how she [the coach] reacts towards me } \\
\text { when learning something new.' (Jaclyn). 'My current head coach does } \\
\text { influence my perception of how well or how quickly I learn. I base } \\
\text { my perceptions on her feedback when I hit and field with her and the } \\
\text { amount of play time I receive.' (Jackie) }\end{array}$ \\
\hline & $\begin{array}{c}\text { Athlete } \\
\text { attributes (29) }\end{array}$ & $\begin{array}{l}\text { 'I just think that growing up and having playing so many sports it's re- } \\
\text { ally easy for me to pick up on new skills and really learn from coach- } \\
\text { ing. And I think and having playing so many sports it's really easy } \\
\text { for me to pick up on new skills and really learn from coaching. And } \\
\text { I think just understanding the game and different concepts of how } \\
\text { different games are played.' (Jill) }\end{array}$ \\
\hline \multirow{3}{*}{$\begin{array}{l}\text { Coach factors } \\
\text { Strategies }\end{array}$} & $\begin{array}{l}\text { Personal best } \\
(20)\end{array}$ & $\begin{array}{l}\text { 'I think of all things actually help build my confidence when she } \\
\text { pushes me to be higher. To be better.' (Colleen) }\end{array}$ \\
\hline & \multirow[t]{2}{*}{$\begin{array}{l}\text { Practice \& } \\
\text { Goals (26) }\end{array}$} & $\begin{array}{l}\text { 'At the end of each practice, she'll put us in game-like situations } \\
\text { where one person will be put in a pressure situation. You know it's } \\
\text { kind of like the game's on the line.' (Colleen) }\end{array}$ \\
\hline & & 'Even if it's a small goal, it's something I can test myself on.'(Jill) \\
\hline & & $\begin{array}{l}\text { "If the coach uses you as a positive example or makes you feel like a } \\
\text { leader on the team, you feel more valued." (Emma) }\end{array}$ \\
\hline Behaviors & Actions (23) & $\begin{array}{l}\text { "I know she'll [the coach] really emphasize the things we are working } \\
\text { on and show how we make an improvement, and actually show } \\
\text { how it impacts a game situation or in practice. Even in camps she'll } \\
\text { definitely mention just like 'oh this player is working on this and she's } \\
\text { doing really, really good.' So just actually verbalizing it to others on } \\
\text { the team, and then they see the importance of what you're working } \\
\text { on and how it's affecting the team overall." (Rylie) }\end{array}$ \\
\hline
\end{tabular}


Table 1 (continued)

\begin{tabular}{ll}
\hline $\begin{array}{l}\text { Encouraging- } \\
\text { corrective (35) }\end{array}$ & $\begin{array}{l}\text { 'She [coach] positively encourages me or reinforces that what I am } \\
\text { doing is correct. Even if I miss up but do something else right, she } \\
\text { will tell me what I did right and what I need to work on next time.' } \\
\text { (Tiffany) }\end{array}$ \\
\cline { 2 - 3 } Communication & $\begin{array}{l}\text { '[Coach] compliments us for doing well and gives us hope to do well } \\
\text { when we mess up.' (Jaclyn) }\end{array}$ \\
\cline { 2 - 3 } & $\begin{array}{l}\text { 'For me to know coach's expectations really helps my motivation and } \\
\text { feelings of competence because I know what she wants from me; } \\
\text { that combined with what I want to do, I am fully aware of what I } \\
\text { need to do to be a successful DI softball player.' (Alicia) }\end{array}$ \\
\hline $\begin{array}{l}\text { Unclear/none } \\
\text { (18) }\end{array}$ & $\begin{array}{l}\text { 'If she's not talking to me that makes me think she doesn't care about } \\
\text { me, so that makes me less motivated.' (Tory) }\end{array}$ \\
\hline
\end{tabular}

Note: Number in parentheses represent the number of athletes reported. The lower-level theme 'Actions' is abbreviated for 'actions display confidence,' and 'Communication' is abbreviated for 'coach-athlete relationship characterized by communication.'

Perceived competence or confidence. Much research confirms the importance of the three basic needs within SDT (Ryan \& Deci, 2000). Perceived competence was defined as the extent to which the athlete believed she had the ability to play softball, personal assessment of ability, and ability to learn new softball skills. Although athletes were provided with a definition of 'competence,' most athletes used the word interchangeably with 'confidence.' Considering SDT is a social-cognitive theory, it is not surprising the athletes linked competence to confidence; however, it is important to note athletes used these terms interchangeably. Results are reported as athletes responded to capture the true meaning of athletes' perspectives. Two subordinate themes emerged that had the most influence on perceived competence: (i) the coach, and (ii) athlete attributes.

The coach factor. Thirty-seven athletes $(90.2 \%)$ believed their current head coach influenced their competence level most often either during instruction sessions $(40.5 \%)$ or after a skill performance $(35.1 \%)$. Hannah's statement embodied this theme and indicated a non-self-determined, but common, reasoning for playing softball, "Coaching definitely is a factor that affects how I feel about how I am doing in softball. Ultimately, in my mind, I'm working to show the coaches I'm capable of performing at this level." Coaches most influenced competence by using praise and encouragement after corrective instruction. The word, or variation of, 'encouraging' was used 15 times when athletes explained if and how their coach affected their competence. Sadie 
illustrated the use of encouragement perceived to increase competence by stating, "She lets us know when we are not playing to our potential but she usually stays a positive and encouraging as possible which I think helps everyone on the field." Although the large majority of athletes reported that the coach did affect perceptions of competence positively, coaches had the potential to affect athletes negatively. The competence of a few athletes $(12.2 \%)$ was inhibited by differential treatment toward players, negative feedback, or an uncomfortable environment created by the coach that 'makes you not play to the best of your ability sometimes.'

Athlete attributes. A second emerging aspect (70.7\%) perceived to influence competence was athletes' personal attributes. Of the 29 athletes that discussed personal attributes as effectors, 26 deemed the coach as the biggest influence on perceived competence or confidence. Personal attributes included the athletes' perception of how coachable she was ('coachability') (e.g., the athlete's rate of improvement, willingness to listen and attempt what the coach requested, speed of skill comprehension) and pre-existing conditions (e.g., confidence level, knowledge base, and stress level). 'Coachability' was explained as, 'if the coach is telling you how to do something, just being able to adapt to the situation that's given to you no matter what the situation is.' Athletes also thought their pre-existing confidence level and knowledge base (influenced by having 'served in a leadership role,' performing as a 'starter' the pervious years, or previous participation in other sports working with other coaches) were competence enhancers.

Coach factors influencing motivation. Two coach-related variables emerged as subordinate themes that influenced motivation: (a) strategies (intentional plans or methods that either enhanced or inhibited motivation to play softball for the current team), and (b) behaviour (observable actions directed at athletes that were considered normal, unintentional interactions).

Coach strategies: meaningful practices and goal setting. Meaningful practice sessions (those that were well-structured, efficient, effective, fun, diverse, competitive) and goal setting strategies were mentioned by $63.4 \%$ of athletes as increasing motivation to play. Athletes enjoyed practices that included 'game-like' situations. Other coaches incorporated a sense of competition between teammates by adding drills that required athletes to compete to perform the best at the given drill, or created a sense of competition to earn a playing position over a teammate. Allison's coach created competition among team members through game simulations, and smaller scaled competitions involving fundamental skill performances, "We will compete. Inter squad kind of, not necessarily scrimmaging, any kind of mini-games that have to do with skill." Athletes like Allison liked the 
competitive drill aspect of practices because "That makes me more motivated because I'm competitive and those competitive juices get flowing."

In addition to competitive elements, meaningful practice sessions were well organized, diverse, and enjoyable. Six athletes (all from different teams) remarked they were motivated to play because their respective coach 'makes practice fun.' In addition to fun practices, athletes preferred practices that involved different drills to diversify practices. Meaningful practice sessions also included goal-setting sessions. Goal-setting strategies included intentional efforts by the coach to set long or short-term goals (team or individual). Athletes were more motivated when coaches communicated goals consistently. Some athletes believed goals motivated them because they had a clear plan or path to follow and they were "centered on [the goal] for that day." All athletes who reported meaningful practice sessions believed their motivation to play increased after these sessions. Although the majority of responses (68.3\%) described enhancing strategies, 16 athletes described a variety of inhibiting strategies (excessive or punishment conditioning sessions, ineffective practice sessions, perceived coach disappointment or doubt in athlete's ability); however, no single strategy emerged as a superordinate theme.

Coach strategies: personal best. A second strategy perceived to enhance motivation was when coaches placed emphasis on the athlete performing at her personal best (48.8\%). Strategies included the coach issuing consistent, positive encouragement to the athlete to focus on her individual success, and encouragement to excel in her performance through hard work. This type of coach behaviour was identified as a strategy because it helped athletes focus on individual improvement and situations each athlete could control rather than the progress of teammates that were beyond their control. Encouragement of personal best was accompanied often with verbal positive feedback of encouragement, reassuring language, or praise. Athletes commented on the coaches' use of 'constant encouragement' to work on skills and improve. For example, Alyssa's coach "makes us all want to work hard to turn our program around" by working hard every day to improve individually and as a team. Nicole was more motivated to play because her coach consistently reminded her she could always improve, "She tells us that we could always be better. And no matter how good we are there's always something to improve on."

Coach behaviors. Several coaching actions were referenced during this study; however, only one emerged as a major contributor athletes perceived to enhance motivation: when coaches' behaviour and words reflected confidence in the athletes' ability to perform successfully (56.1\%). Brooke's coach consistently verbalized her confidence to Brooke during instruction and games: 
I can tell my coach believes in me not only when she tells me out loud, but also from her actions. As a pitcher, the game is in your hands. My coach has confidence in me and gives me the game ball most of the time. She always encourages me and tells me that I can be the best pitcher in the country. Before games, in between innings, and at practice, she tells me that I am doing a great job and that there is not a hitter in the conference that can touch me, as long as I continue to work the way I do and stay healthy.

More specifically, athletes perceived motivation was enhanced when coaches emphasized an athlete's leadership role to the individual athlete. For example, when Brooke's coach informed her he 'is building the team around me', and Allison believed her coach "encourages leadership" and supported her approach because "if I approach him with something, he backs it up." Additionally, athletes were motivated when the coach selected the athlete to model a skill performance for other teammates or spectators during practice sessions or clinic settings because athletes attributed this to the coach's confidence in their ability. Although discussed, no behaviors emerged as having a perceived major inhibiting influence on motivation (e.g., benching athlete, un-justified frustration behaviors).

Perceived coach-atblete communication. The third and most influential superordinate theme that emerged was aspects relating to coach-athlete relationship characteristics, specifically verbal communication by the coach to the athlete. Several subordinate themes emerged: (i) verbal feedback, (ii) open, clear, direct communication, and (iii) absence or avoidance of communication. The perception of coach-athlete communication type had the overall largest perceived influence on confidence and motivation.

Coach feedback. Athletes provided numerous examples of feedback types, both verbal and non-verbal, perceived to enhance or inhibit motivation and confidence. All athletes $(n=41)$ described some form of positive feedback as enhancing motivation or confidence although coach feedback type was most often discussed in relation to enhancing confidence. The two most frequently mentioned influential forms of feedback were: (a) encouragement followed by corrective instruction, and (b) praise. No form of feedback emerged as a major inhibitor of motivation or competence.

Encouragement and corrective. Athletes (85.4\%) described the coach's use of re-assuring language or encouragement after a performance paired with corrective instruction as positive feedback athletes perceived enhanced both motivation and confidence. Athletes used this type of feedback as an indicator 
that they were performing skills correctly. Overall, athletes appreciated when coaches encouraged them to persist and told them 'how to fix it' so they 'can feel more confident in what I'm doing.' Kayla's example captured this theme, "She encourages me. Tells me what I'm doing wrong, but then tells me how to fix it. So like even if I am doing something wrong I know how to fix it so I can feel more confident in what I'm doing. [She] tells me what I'm doing right.'” This combination of feedback was the second most common aspect overall perceived to enhance motivation.

Praise. Responses coded under the praise category involved feedback recognizing the athlete for any successful behaviour, and were reported by $65.9 \%$ of athletes. Athletes appreciated with the coach was "the first to say 'good job."' Others were motivated by the emphasis the coach placed on effort made rather than outcome of performance. Alyssa elaborated on her coach's positive influence by explaining, "The thing I love about coach is you don't even have to make a great play for her to compliment you; all you have to do is put in the effort." Some athletes believed that when the coach made an effort to personally recognize their effort, their confidence also increased because they felt they were bringing a valuable element to the team and contributing to success.

Open, clear, and direct communication. Athletes' perception of a coach-athlete relationship involving open, clear, or direct communication (95\%) was the single most influential aspect in feelings of motivation and confidence. This type of communication was described most often in connection with coaches' discussion with athletes about expectations of athletes' performance. Athletes were more motivated and confident in their ability to reach their coach's expectations when the coach clearly communicated what the coach expected. The athletes in this study reported direct verbal communication during scheduled meetings or impromptu discussion with their coach about expectations and goals for individual practice outcomes and improvement. Hannah appreciated her coach's direct communication and was more motivated to practice and play because "then I know what I need to work toward. It keeps my mind on something specific to work toward every day." Clear communication about expectations enabled athletes to "work harder to meet those expectations." This type of communication was an indicator to athletes that the coach made an effort to understand each player individually and form a personal relationship. Athletes also appreciated this form of communication during corrective instruction. One athlete captured this theme by expressing a desire to "know exactly what [the coach] wants. I do not like the guessing game."

Unclear or absence of communication. The majority of responses of perceived relationship were positive, but athletes $(48.8 \%)$ did describe negative elements of the relationship. Of these athletes, $90 \%$ reported motivation or confidence 
was inhibited when the coach offered unclear communication (indirect methods or lack of clarity) or did not communicate with the athlete. Absence of communication was characterized as the coach ignoring the athlete (avoided interaction) or performance (silence) and offering no feedback. This theme was the only theme that emerged as a major inhibitor of confidence or motivation.

Athletes noticed after poor performances - most often in game situationstheir coaches ignored them when the athletes looked to the coaches for feedback about the performance. Athletes reported this behaviour made them feel less confident (not competent) about their abilities because "you don't know what she's thinking or what she feels about how things went." Other avoidance tactics included avoiding eye contact with the athlete and creating noticeably larger physical distance between the athlete and the coach. Athletes were least motivated when the coach "doesn't acknowledge me at all." Jamie's frustration captured others' thoughts about the coach after a poor performance because athletes' wanted direction on how to fix the mistake instead of no constructive feedback:

If I messed up a play or something and I look over and I just see her shaking her head, it's like “oh crap!" Like I didn't know I did it wrong, I understand that, but it just sucks to see, and I'd rather just have her call me over and be like, "Hey you could of done this" or "You could of done that." I just keep thinking about it [the mistake] and I won't be better.

If athletes were unsure of the meaning of the coach's verbal communication the confusion and unclarity inhibited motivation. One athlete explained an over-arching theme that she has to "pick up on things myself" because she was unsure of a variety of issues (performance expectations, skill correction, team rules, directions, value to team). Athletes felt when they "aren't on the same page" as the coach they could not understand "where [the coach is] coming from."

\section{Discussion}

The purpose of this study was to examine female collegiate athletes' perspectives on specific coaching behaviors that influence their motivation to play softball. Overall, softball athletes had positive perceptions of their coaches' behaviors, and desired a coach-athlete relationship that emphasized open, direct, and clear communication guided by praise and encouraging-corrective feedback. Additionally, athletes' experiences provided insight into other issues pertaining to motivation and competence that warrant discussion. While many of the findings 
of the present study support previous findings, this is the first qualitative study to directly relate results to the components of SDT.

To examine the role of competence on motivation, SDT was used as a guide. Several researchers have provided support for feelings of competence having a mediating effect on intrinsic motivation (e.g., Amorose \& Horn, 2001; Weiss \& Ferrer-Caja, 2002); however, except in a few instances, athletes in this study generally isolated responses to either motivation or competence influencers rather than considering these two factors together except in a few instances. However, athletes in this study repeatedly used the term 'competence' and 'confidence' interchangeably (despite being provided with a definition of 'competence'), and responses more closely resembled feelings of 'confidence' indicating athletes were not clear on the distinction between the two terms. Some researchers have examined the issue of using these two terms interchangeably (Stewart, O'Halloran, Barton, Singleton, Harrigan, \& Spencer, 2000), and there was confusion on what these terms meant to participants in this study. Regardless, similar to Amorose (2003), athletes believed their head coach was the greatest influencer of perceptions of competence or confidence more so than any other variable. Furthermore, the primary reasons athletes provided for general motivation to play aligned with the three basic needs of SDT rather than a single need (Deci \&Ryan, 2000). Athletes reported motivation to play for their team because of relationships with teammates (relatedness), to win or be the best (competence), and enjoyment of the sport itself indicating they chose to participate (autonomy).

Also of importance was the feedback type athletes presented as positive influencers. Athletes clearly preferred positive feedback in the form of encouragement paired with corrective instruction and praise. This finding is not surprising given other studies have shown similar results through both quantitative and qualitative measures (Gearity, 2012; Hodge et al., 2014; Hollembeak \& Amorse, 2005; Turman, 2003b). Athletes for this study were highly self-determined in their motivation to play for their current team, and reported mostly positive instances of coaching behaviour. This finding is also consistent with previous studies that athletes who are more self-determined generally report more instances of positive training and instructional feedback (see reviews by Vallerand, 2007; Weiss \& Amorose, 2008). This generation of athletes are capable and comfortable indicating what types of coaching behaviors they not only prefer (Gearity, 2012; Hodge et al., 2014; Hollembeak \& Amorse, 2005; Horn et al., 2011), but behaviors that will help them succeed. The softball athletes in this study were not different. They distinctly identified encouragement and corrective instruction as preferred and necessary feedback to enhance motivation and competence. SDT (Ryan \& Deci, 2000) can be used 
to explain this finding. Considering this highly self-determined sample, athletes may not perceive they need their coach to motivate them through external forms of regulation (e.g., issuing punishment), but rather desire a coach who facilitates learning opportunities and encourages the athlete to persist through difficulty. This finding lends qualitative support to Horn et al.'s (2011) quantitative examination of preferred coaching behaviors.

An interesting finding of this study was the emergence of the perception of type of coach communication as the most influential factor on motivation. Nearly every athlete reported feeling more confident (rather than competent) or motivated when their coach shared explicit performance expectations and corrective instruction, specifically after a performance attempt. As expected, athletes placed value on their coach's feedback and opinion as expected (Bell, 1997; Jowett, 2010), and most wanted some form of acknowledgement of their performance; therefore, athletes reported feeling less confidant when they did not know what skill to correct or if they were unsure if their performance pleased their coach. Literature is clear that positive coach behaviors enhance a variety of psychological factors (self-concept, self-esteem, motivation, satisfaction: Adie \& Jowett, 2010; Jowett \& Cramer, 2010; Sager \& Jowett, 2012), and has primarily focused on the influence of coaches' form of feedback or behaviors on athletes' motivation (e.g., Amorose \& Horn, 2001, 2003; Amorose \& Weiss, 1998). While others have examined the influence of coaches' leadership styles, the measures used included only a small subscale assessing communication (e.g., Hodge et al., 2014; Hollembeak \& Amorose, 2005; Sherman et al., 2000) with little emphasis on consistency and directness of the message from coach to athlete. Research has not focused solely on the impact of communication on the coach-athlete relationship or motivation. In the current study, when coaches did not communicate, athletes felt they did not meet their coaches' expectations, and this finding is consistent with other studies (Jowett, 2009; Martin, Rocca, Cayanus, \& Weber, 2009; Sager \& Jowett, 2012), but when coaches practiced positive communication, athletes' motivation and confidence were reinforced. The emergence of communication type alone as a major influence of motivation and confidence for female collegiate athletes is an interesting finding that could be useful to coaches at all levels. Similar findings emerged from Fasting and Pfister's (2000) and Norman and French's (2013) qualitative study of elite female athletes. In both studies, the type of communication required from the coach is defined, specific, and the current study supports those findings. The presence and type of communication may serve as a social factor per SDT and be an indication of external regulation (Ryan \& Deci, 2000), and would explain the influence of communication on motivation. 
A somewhat unexpected coaching strategy that influenced motivation was when coaches conducted meaningful practice sessions. Meaningful practice sessions incorporated a variety of elements, and the most common elements that emerged were sessions that included short or long-term goal-setting or competitive drills,. Research on the benefits and need for goal setting as a method to directly influence motivation is extensive (see Roberts \& Treasure, 2012 for a review). Athletes in this study tended to refer to mastery goal strategies and performance climates similar to other studies (Ames, 1992) and should be expected from highly self-determined athletes (Ryan \& Deci, 2000). This finding is positive and consistent with SDT because it indicates coaches were creating positive, mastery motivational climates that are desired to enhance self-determined motivation. Athlete responses in the current study illustrate the presence of the continuum of motivation within environment as goal setting is a form of identified regulation and coach feedback is considered external regulation (non-self-determined) (Ryan \& Deci, 2000; Pensgaard \& Roberts, 2002; Smith et al., 2010; Turman, 2003b; White et al., 2006).

Included in meaningful practice sessions was the coaches' incorporation of competitive drills. Athletes repeatedly expressed their desire for a variety of game-like situations and competition in practice. Although this finding may not be surprising to coaches considering this study involved high-level athletes, there is no research that was found to support competitive drills as a method to enhance motivation. Examining SDT, the use of competitive drills could align with identified regulation as a form of a self-determined motivation (Ryan \& Deci, 2000) if athletes place internal value on the need for competition or variety of drills to increase enjoyment. However, if athletes desire competition against teammates to maintain their sense of self-worth then this could be a more nonself-determined reason (introjected regulation). Although a combination of selfdetermined and extrinsic forms of motivation are needed to enhance overall success (Ryan \& Deci, 2000), it is important for the coach to understand why athletes participate in a drill or performance so he or she can be aware of what the behaviour (drill) is fulfilling for the each athlete. In the sport environment, coaches often treat competitive drills as a form of performance assessment and tell players to 'practice like you play' meaning athletes must practice in a competitive mind-set to be physically, mentally, and emotionally prepared to perform in actual competitions. The 'practice like you play' approach may serve a dual purpose for coaches.

\section{Limitations and Future Directions}

As with all research, some limitations to the present study must be discussed. Although 25 teams were represented, some teams only had one or 
two athletes reporting about a particular coach. Ideally, data collection for each coach should continue until saturation occurs and triangulate to capture a more accurate description of coaching behaviors specific to that coach. Clustering data by coach and then comparing codes across coaches for overarching themes could provide a more in-depth examination of coaching behaviors specific to personal characteristics of the coach, team competition level, and unique team cultures. Future projects should attempt these more comprehensive procedures.

Descriptive information provided interesting information about these athletes as more than half $(58.5 \%)$ had played for their head coach for less than one year for various reasons (transfer, new coach, freshman), and at the time of data collection, athletes would have only interacted regularly with their coaches for approximately four months. The majority of responses pertained to positive coaching behaviors, and is a positive finding; however, the question arises as to how did the length of time athletes' played for coaches influence perceptions? Other studies involving first year collegiate athletes indicate these athletes tend to report more positive types of feedback as enhancing motivation than more tenured athletes (Amorose \& Horn, 2001; Hollembeak \& Amorose, 2005). Also, examining perceptions during or after the competitive playing season could enhance the literature by providing a source of comparison. Research should attempt triangulation with this type of issue, and findings could be used to compare to other sports (team, individual, male, female) to examine differences in perceptions of behaviour.

Finally, the majority of athletes $(n=33)$ submitted responses about a female head coach. Considering the rise in male head coaches within this sport (LaVoi, 2014), this sample was not representative of this trend. Teams were selected through random cluster sampling used for the larger mixed methods study from which the data was collected, and athletes' perceptions of differences in characteristics between male and female coaches was not adequately represented. The research on feedback type and communication differences between male and female head coaches has been inconclusive. Some literature reports there are no differences in leadership style, including feedback type, between the two genders (Jambor \& Zhang, 1997), and some literature reports minimal differences in communication style (e.g., authoritative) (Haselwood, Joyner, \& Burke, 2000; Satyanarayana \& Chaganti, 2011). The current study provides limited support for positive coach behaviors from both genders with no clear indication of differences from coach gender. Research may extend to examining communicator styles (Norton, 1983) of the coach including coach and athlete perceptions and how perceptions of communicator style influence athlete motivation and performance. Future efforts should include a more balanced sample among coaches, as few male coaches were represented here. 


\section{Conclusion}

Qualitative research methods were implemented to examine the coachrelated reasons behind how female softball players lose or gain motivation and competence. This subjective approach allowed for the voice of the athlete to be heard on how and why certain coach behaviors influence their motivation rather than relying on numbers to describe feelings or perceptions. A large sample size (for qualitative research) helped establish reliability of the emergent themes, and should be considered a strength of this study. Generally, qualitative studies examine much smaller sample sizes (Cresswell, 2009). Although some findings supported quantitative results from other studies, other findings emerged that may not have if quantitative methods were used (e.g., communication, actions displaying confidence, practice sessions). Practical implications. Female softball athletes identified specific behaviors and feedback patterns they believed hurt or enhanced motivation to play that can be useful to coaches of female athletes. Coaches should reflect on these findings and assess of how he or she responds both verbally and nonverbally to athletes. Becoming aware of behaviors is one of the first steps in behavior modification (Miltenbeger, 2012), and modification may require time and practice. One way coaches can monitor behavior and strengthen communication lines with female athletes is to incorporate both planned and unplanned coach evaluations throughout the seasons. Specific to the results of this study, coaches are encouraged to consistently communicate expectations about athletes and athlete progress through formal and informal conversations. During these conversations, coaches could engage athletes by asking athletes to provide expectations they have for the coach accompanied by coach progress reports. Opening the dialogue between coach and athlete will not only strengthen the perception of communication, but will assist with enhancing perceptions of the three basic psychological needs (Ryan \& Deci, 2000).

Coaches should be intentional about communicating performance expectations clearly and consistently directly to athletes. Female athletes in this study appreciated frequent meetings (informal and formal) where the coach informed them exactly what the expected from them. This may be different from what male athletes or coaches desire or need; however, coaches need to pay attention to these differences in what athletes need to succeed. Coaches should be cautious in ignoring female athletes' performance attempts, and should be prepared to respond with not only encouragement but also corrective instruction. This may be another finding that is specific to female athletes or to athletes of this generation (although more research is needed around this issue) that coaches need to consider. Athletes provided examples of different types of motivation explained by SDT that coaches should familiarize themselves 
with (reasons for motivation). Coaches may be able to incorporate a strategy to move athletes through the continuum toward more self-determined reasons to play. Creative coaching approaches in the form of drills and team-building may assist in generating desired motivation. For example, coaches may try rewarding athletes with small external rewards (e.g., favorite candy) accompanied by verbal and non-verbal actions (e.g., high-fives, praise) after the athlete accomplishes a task. An example of this type of behavior is displayed at the Women's College World Series games when coaches are seen tossing pieces of candy to athletes as they round third base after hitting a homerun. This is primarily an example of fostering external regulation; however, athletes need this type of motivation in addition to self-determined motivation (Vallerand \& Bissonnette, 1992). Moving toward more self-determined motivation, coaches could foster all three basic needs (not just competence) by allowing athletes to plan and implement either a portion of practice or an entire practice session. These are just a couple of examples, and coaches are encouraged to be creative in how they engage their female athletes in the coaching process.

Finally, many of the communication issues discussed are skills that can be taught or enhanced through formal training from local professionals (e.g., counsellors, psychologists). Coaches should approach practices and games with intentional strategies prepared. Incorporating a variety of competitive drills in practice, implementing goal setting, and encouraging athletes to perform her personal best will foster female athletes' motivation. Coaches have a strong influence on athletes, and steps should be taken to ensure they are actively pursuing education that will improve their coaching skills to positively influence the athletes they mould.

\section{Acknowledgements}

The first author would like to acknowledge Dr. Lori A. Wolff and her guidance as the dissertation advisor and author mentor.

\section{References}

Adie, J., \& Jowett, S. (2010). Athletes' meta-perceptions of the coach-athlete relationship, multiple achievement goals and intrinsic motivation among track and field athletes. Journal of Applied Social Psychology, 40, 2750-2773.

Ames, C. (1992). Achievement goals, motivational climate, and motivational processes. In G. C. Roberts (Ed.), Motivation in sport and exercise (pp. 161-176). Champaign, IL: Human Kinetics. 
Amorose, A. J. (2003). Reflected appraisals and perceived importance of significant others' appraisals as predictors of college athletes' self-perceptions of competence. Research Quarterly for Exercise and Sport, 74, 60-70.

Amorose, A. J., \& Horn, T. S. (2000). Intrinsic motivation: Relationships with collegiate athletes' gender, scholarship status, and perceptions of their coaches' behaviour. Journal of Sport \& Exercise Psychology, 22, 63-84.

Amorose, A. J., \& Horn, T. S. (2001). Pre- to post-season changes in the intrinsic motivation of first year college athletes: Relationships with coaching behaviour and scholarship status. Journal of Applied Sport Psychology, 13, 355-373.

Amorose, A. J., \& Weiss, M. R. (1998). Coaching feedback as a source of information about perceptions of ability: A developmental examination. Journal of Sport \& Exercise Psychology, 20, 395-420.

Athnet. (2014). History of softball. Athnet: Get recruited to play college sports. Retrieved from http://www.athleticscholarships.net/

Baker, C., Wuest, J., \& Stern, P. N. (1992). Method slurring: The grounded theory/phenomenology example. Journal of Advanced Nursing, 17, 1355-1360.

Balaguer, I., Duda, J., Atienza, F., \& Mayo, C. (2002). Situational and dispositional goals as predictors of perceptions of individual and team improvement, satisfaction and coach ratings among elite female handball teams. Psychology of Sport and Exercise, 3(4), 293-308.

Beam, J., Serwatka, T., \& Wilson, W. (2004). Preferred leadership of NCAA Division I and II intercollegiate student-athletes. Journal of Sport Behavior, 27(1), 3-17.

Beauchamp, P. H., Halliwell, W. R., Fournier, J. F., \& Koestner, R. (1996).

Affects of cognitive-behavioral psychological skills training on the motivation, preparation, and putting performance of novice golfers. The Sport Psychologist, 10, 157-170.

Bell, C.C. (1997). Promotion of mental health through coaching competitive sports. Journal of the National Medical Association, 89, 517-520.

Côte, J, Ericsson, K.A., \& Law, M.P. (2005). Tracing the development of athletes using retrospective interview methods: A proposed interview and validation procedure for reported information. Journal of Applied Sport Psychology, 17, 1-19. 
Cresswell, J. W. (2009). Research design: Qualitative, quantitative, and mixed method approaches (3rd ed.). Thousand Oaks, CA: Sage Publications.

Deci, E. L. \& Ryan, R. M. (1985). Intrinsic motivation and self-determination in human behavior. In Deci, E. L., \& Ryan, R. M. (Ed.). Intrinsic motivation and self-determination in buman behavior (pp. 43-85). New York: Plenum.

Deci, E. L., \& Ryan, R. M. (1991). A motivational approach to self: Integration in personality. In R. Deinstbier (Ed.), Nebraska Symposium on Motivation: Vol. 38. Perspectives on Motivation (pp. 237-288). Lincoln, NE: University of Nebraska Press.

Duda, J. (1989). Relationship between task and ego orientation and perceived purpose of sport among high school athletes. Journal of Sport \& Exercise Psychology, 11, 318-335.

Faster, K. \& Pfister, G. (2000). Female and male coaches in the eyes of female elite soccer players. European Physical Education Review, 6(1), 91-110.

Flynn, M. (1995). Softball slides into the 21st Century. Parks and Recreation, 30(4), 36-42.

Gearity, B. T. (2011). Poor teaching by the coach: A phenomenological description from athletes' experience of poor coaching. Physical Education and Sport Pedagogy, iFirst Article, 1-18.

Gearity, B. T., \& Murray, M. A. (2010). Athletes' experiences of the psychological affects of poor coaching. Psychology of Sport and Exercise, 12, 213-221.

Greenleaf, C., Gould, D., \& Dieffenbach, K. (2001). Factors influencing Olympic performance interview with Atlanta and Nagano U.S. Olympians. Journal of Applied Sport Psychology, 13(2), 154-184.

Hein, V., Müür, M., \& Koka, A. (2004). Intention to be physically active after school graduation and its relationship to three types of intrinsic motivation. European Physical Education Review, 10(1), 5-19.

Hollembeak, J., \& Amorose, A. J. (2005). Perceived coaching behaviors and college athletes' intrinsic motivation: A test of self-determination theory. Journal of Applied Sport Psychology, 17, 20-36. 
Horn, T. S., Bloom, P., Berglund, K. M., \& Packard, S. (2011). Relationship between collegiate athletes' psychological characteristics and their preferences for different types of coaching behaviour. The Sport Psychologist, 25, 190-211.

Jambor, E. A., \& Zhang, J. J. (1997). Investigating leadership, gender, and coaching level using the Revised Leadership for Sport Scale. Journal of Sport Behavior, 20(3), 313-320.

Jowett, S. (2007). Interdependence analysis and the $3+1 \mathrm{Cs}$ in the coach-athlete relationship. In S, Jowett \& D. Laveallee (Eds.), Social psychology in sport (pp. 1527). Champaign, IL: Human Kinetics.

Jowett, S. (2009). Validating coach-athlete relationship measures with the nomological network. Measurement in Physical Education and Exercise Science, 13, 1-18.

Jowett, S., \& Cramer, D. (2010). The prediction of young athletes' physical self from perceptions of relationships with parents and coaches. Psychology of Sport and Exercise, 11, 140-147. doi:10.1016=j.psychsport.2009.10.001

LaVoi, N. M. (2014, January). Head coaches of women's collegiate teams: A report on select NCAA Division-I FBS institutions, 2013-14. Minneapolis: The Tucker Center for Research on Girls \& Women in Sport.

MacKinnon, V. (2011). Techniques for instructing female athlete in traditionally male sports: A case study of LPGA teaching professionals. The International Journal of Sport and Society, 2(1), 75-87.

Marin, S., Dale, G., \& Jackson, A. (2001). Youth coaching preferences of adolescent athletes and their parents. Journal of Sport Behavior, 24(2), 197-212.

Martin, M. M., Rocca, K. A., Cayanus, J., \& Weber, K. (2009). Relationships between coaches' use of behaviour alteration techniques and verbal aggression on athletes' motivation and affect. Journal of Sport Behavior, 32, 227-241.

Miltenberger, R. (2012). Measurement of behaviour and behaviour change. Behavior modification: Principles \& Procedures (pp. 1-39). Belmont, CA: Wadsworth.

Norman, L., \& French, J. (2013). Understanding how high performance women athletes experience the coach-athlete relationship. International Journal of Coaching Science, 7(1), 3-24.

NVivo qualitative data analysis software Version 9 (2010). QSR International Pty Ltd. 
Olympic Movement. (2014, May). Factsheet: Women in the Olympic Movement. A report commissioned by the International Olympic Committee. Retrieved from www. olympic.org

Opdenakker, R. (2006). Advantages and disadvantages of four interview techniques in qualitative research. Forum: Qualitative Social Research, 7(4). Retrieved from http://www.qualitative-research.net/index.php/fqs/article/ view $/ 175 / 391$

Patton, M. Q. (2002). In C. D. Laughton \& V. Novak (Eds.), Qualitative research and evaluation methods (3rd ed.). Thousand Oaks, CA: Sage Publication, Inc.

Pelletier, L. G., Fortier, M. S., Vallerand, R. J., \& Brière, N. M. (2001). Associations among perceived autonomy support, forms of self-regulation, and persistence: A prospective study. Motivation and Emotion, 25, 279-306.

Pollio, H. R., Henley, T. B., \& Thompson, C. J. (1997). The phenomenology of every day life (pp. 28-56). New York, NY: Cambridge University Press.

Riemer, H., \& Toon, K. (2001). Leadership and satisfaction in tennis: Examination of congruence, gender, and ability. Research Quarterly for Exercise and Sport, 72(3), 243-256.

Ryan, R. M., \& Connell, J. P. (1989). Perceived locus of causality and internalization: Examining reasons for acting in two domains. Journal of Personality and Social Psychology, 57, 749-761.

Ryan, R. M., \& Deci, E. L. (2000). Self-determination theory and the facilitation of intrinsic motivation, social development, and well-being. American Psychologist, 55(1), 68-78.

Sager, S., \& Jowett, S. (2012). Communicative acts in coach-athlete interactions: When losing competitions and when making mistakes in training. Western Journal of Communication, 76(2), 148-174.

Satyanarayana, S. V., \& Chaganti, V. K. (2011). Gender and dyadic perceptions of communication style: Does reciprocation mean more? Management Convergence, 1(2), 1-9.

Sherman, C., Fuller, R., \& Speed, H. (2000). Gender comparisons of preferred coaching behaviors in Australian sports. Journal of Sport Behavior, 23(4), 389406. 
Sinkovics, R. R. (2008). Enhancing the trustworthiness of qualitative research in international business. Management International Review, 48(6), 689-713. DOI 10.1007/s11575-008-0103-z

Smith, A., Ntoumanis, N., \& Duda, J. (2010). An investigation of coach behaviors, goal motives, and implementation intentions as predictors of well-being in sport. Journal of Applied Sport Psychology, 22, 17-33.

Smith, R. E., Smoll, F. L., \& Barnett, N. P. (1995). Reduction of children's sport performance anxiety through social support and stress-reduction training for coaches. Journal of Sport Psychology, 1, 59-75.

Turman, P. D. (2003a). Coaches and cohesion: The impact of coaching techniques on team cohesion in small group sport setting. Journal of Sport Behavior, 26(1), 86-104.

Turman, P. D. (2003b). Athletic coaching from an instruction communication perspective: The influence of coach experience on high school wrestlers' preferences and perception of coaching behaviors across a season. Communication Education, 52(2), 73-86.

Vallerand, R. J. (2000). Deci and Ryan's self-determination theory: A view from the hierarchical model of intrinsic and extrinsic motivation. Psychological Inquiry, 11(4), 312-318.

Vallerand, R. J. (2007). A hierarchical model of intrinsic and extrinsic motivation for sport and physical activity. In S. Martion, N. Chatzisarantis (Eds.), Intrinsic motivation and self-determination in exercise and sport (pp. 255-279). Champaign, IL: Human Kinetics.

Vallerand, R. J., \& Bissonnette, R. (1992). Intrinsic, extrinsic, and a motivational styles as predictors of behavior: A prospective study. Journal of Personality, 60(3), 599-620.

Vallerand, R. J, \& Fortier, M. S. (1998). Measures of intrinsic and extrinsic motivation in sport and physical activity: A review and critique. In J. Duda (Ed.) Advances in sport and exercise psychology measurement (pp. 81-101). Morgantown, WV: Fitness Information Technology.

Vallerand, R. J., \& O'Conner, B. P. (1989). Motivation in the elderly: A theoretical framework and some promising findings. Canadian Psychology, 30, 538-550. 
Wang, J. C. K., Koh, K. T., \& Chatzisarantis, N. (2009). An intra-individual analysis of players' perceived coaching behaviors, psychological needs, and achievement goals. International Journal of Sports Science ¿ Coaching, 4(2), 177-192.

Weiss, M. R., \& Amorose, A. J. (2008). Motivational orientations and sport behaviour. In T.S. Horn (Ed.), Advances in sport psychology (3rd ed., pp. 115-155). Champaign, IL: Human Kinetics.

Weiss, M. R., \& Ferrer-Caja, E. (2002). Motivational orientations and sport behaviour. In T. S. Horn (Ed.), Advances in sport psychology (2nd ed., pp. 101114). Champaign, IL: Human Kinetics.

Women's Sport Foundation. (2008). Once Upon a Time Before Title IX. Retrieved June 8, 2011 from http://www.womenssportsfoundation.org

\begin{abstract}
Megan M. BUNING, Ph.D., is an Assistant Professor of Research at Augusta University (formally Georgia Regents University) where she has been for the past two years. She earned her Ph.D. in Higher Education Administration at the University of Mississippi. Prior to faculty appointment, she served as a Division I softball coach for seven years. During her coaching tenure, she began her research examining athlete motivation and perceptions of coaching behavior. Her current research areas include defining and capturing the sense of athletic entitlement, the use of athletic vision training to enhance reading performance, and the influence of targeted STEM programming on students' attitudes towards STEM classes in the middle grades.
\end{abstract}

\title{
Corresponding address:
}

Megan M. Buning

Georgia Regents University; Augusta University

2500 Walton Way, UH Ste 325,

Augusta, GA 30904

E-mail: mbuning@gru.edu

Phone: (706)729-2921

Melissa THOMPSON, Ph.D., is an Associate Professor of Sport Coaching Education at the University of Southern Mississippi. Her areas of research include coaching ethics and the coaching internship process as a means of developing coaching efficacy and coaching reflection. She holds a doctorate in Sport and Exercise Psychology from Florida State University, is a Certified Consultant through the Association of Applied Sport Psychology, and is a Certified Strength and Conditioning Specialist through the National Strength and Conditioning Association. E-mail: m.thompson@usm.edu 